\title{
Entre a natureza e a floresta xamânica: uma exposição do fim do mundo à luz das palavras do xamã Davi Kopenawa
}

\author{
Entre la naturaleza y el bosque chamánico: una exposición del fin del \\ mundo a la luz de las palabras del chamán Davi Kopenawa
}

\section{Between nature and the shamanic forest: an exhibition to the the end of the world enlightened by the words of the shaman Davi Kopenawa}

Pedro Paulo Valerio Vaz ${ }^{1}$

\begin{abstract}
Resumo
Este artigo busca fazer uma reflexão junto às palavras do xamã yanomami Davi Kopenawa contidas na obra $A$ queda do céu, construída em conjunto com o antropólogo Bruce Albert. O ponto central explorado será a relação que o xamã estabelece com os não-humanos, com os espíritos, com a floresta encantada. Neste sentido este artigo busca expor aquilo que só os xamãs veem, conhecem, que é o sobrenatural, o mundo animado. Resumidamente, o que se tenta fazer é comparar o texto xamânico com outros ocidentais, para que as diferenças e a semelhanças entre eles sejam expostas. As relações que os xamãs estabelecem com as florestas estão intimamente ligadas a questão do fim do mundo, a questão da catástrofe ambiental, e sendo assim, este artigo irá expor diferentes versões do fim do mundo já escritas por ocidentais, para então as compara las ao fim do mundo xamânico. O resultado é um texto que fica sempre em um limite entre o mundo branco e o mundo yanomami, e que construiu uma possível entrada das palavras do xamã Davi Kopenawa para dentro da antropologia, e de suas questões.
\end{abstract}

Palavras-chave: florestas; xamanismo; espíritos, fim do mundo; não-humanos.

\section{Resumen}

Este artículo busca hacer una reflexión junto a las palabras del chamán yanomami Davi Kopenawa contenidas en la obra A queda do céu, construida en conjunto con el antropólogo Bruce Albert. El punto central explorado será la relación que el chaman establece con los no humanos, con los espíritus, con el bosque encantado. En este sentido este artículo busca exponer lo que sólo los chamanes ven, conocen, que es lo sobrenatural, el mundo animado. Resumidamente, lo que se intenta hacer es comparar el texto chamánico con otros textos occidentales, para que las diferencias y las similitudes entre ellos sean expuestas. Las relaciones que los chamanes establecer con los bosques están íntimamente ligadas a la cuestión del fin del mundo, la cuestión de la catástrofe ambiental, y siendo así, este artículo expondrá diferentes versiones del fin del mundo ya escritas por occidentales, para entonces compararlas al fin del mundo chamánico. El resultado es un texto que está siempre en un límite entre el mundo blanco y el mundo yanomami, y que construyó una posible entrada de las palabras del shaman Davi Kopenawa hacia dentro de la antropología, y de sus cuestiones.

Palabras claves: bosques; chamanismo; espíritus; fin del mundo; no humanos.

\begin{abstract}
This article seeks to produce reflections within the words of the yanomani shaman Davi Kopenawa, contained in the work The falling sky, built along with the anthropologist Bruce Albert. The main point explored will be the relation that the shaman establish with the nonhumans, spirits, and the enchanted forest. In this sense, this paper aims to expose what only shamans see and know, which is the supernatural, the animate world. Briefly, the main point is to compare the shamanic text with other Western texts, so that the differences and similarities can be exposed. The relations that shamans establish with the forest are closely related with the issues around the end of the world, such as the environmental catastrophe questions, and thus, this paper will to expose different versions
\end{abstract}

\footnotetext{
${ }^{1}$ Mestrado em Antropologia pelo Departamento de Ciencias Humanas e Filosofia; Universidade Federal de Minas Gerais; Belo Horizonte, Minas Gerais, Brasil; pedroovalerio@gmail.com.
} 
of the end of the world already written by westerners, then seeks to make comparison with the shamanic end of the world. The result is a text that always lies between the white world and the yanomami world, that constructed a possible entry from the words of the shaman Davi Kopenawa into the anthropology and its questions.

Keywords: forests; shamanism; spirits; end of the world; nonhumans.

\section{Introdução}

A obra $A$ queda do céu, que nasceu da cooperação entre o xamã Davi Kopenawa, e o antropólogo Bruce Albert, foi publicada e traduzida, recentemente, para línguas do ocidente ${ }^{2}$, e este artigo busca cooperar na exposição dos efeitos que a obra xamânico-antropológica vem causando à tradição escrita ocidental. Ir ao encontro da questão específica do fim do mundo xamânico, para que suas características sejam expostas e colocadas em relação aos diferentes fins do mundo propostos pelos ocidentais, é o objetivo desse texto. Os não-humanos, os espíritos, são personagens decisivos para se entender a cosmologia Yanomami narrada por Kopenawa e, por consequência, para se entender o fim do mundo xamânico. Quando se trata da queda do céu, da catástrofe natural que está por vir, o espírito chamado de ser do caos (Xiwãripo) é o principal personagem. O texto remeterá as próprias palavras do xamã para acompanhar sua exposição do mundo dos espíritos, e a relação deste mundo com os brancos e, logo, com o fim do mundo.

Irá se expor, no início deste texto, diferentes possíveis fins do mundo já descritos pelos ocidentais, para então caminhar para as próprias palavras do xamã e, então, expor algumas características do fim do mundo específicas da cosmologia Yanomami narrada por Davi Kopenawa. Busca-se menos fazer os textos ocidentais ${ }^{3}$ convergirem para as afirmações de Kopenawa, e mais expor as divergências entre os vários possíveis fins do mundo que serão apresentados, pensando os possíveis efeitos, tremores e tensões que as afirmações xamânicas implicam à tradição moderna escrita. Resumidamente, o que se tenta fazer aqui é friccionar o texto xamânico com outros textos ocidentais, de forma que surjam caminhos em comum, desvios, ou mesmo para que seja possível descrever as faíscas do atrito desses encontros.

Umas das partes deste artigo irá se concentrar em expor aquilo que só os xamãs veem, sabem, conhecem, que é o sobrenatural/extranatural/supernatural, o mundo animado, povoado

\footnotetext{
${ }^{2}$ O livro teve sua primeira publicação em uma língua ocidental na França, no ano de 2010.

${ }^{3}$ Este artigo propõe uma exposição dos argumentos de diferentes escritores ocidentais, sejam antropólogos, filósofos, cientistas. Os diferentes textos de diferentes escritores serão apresentados ao longo do texto, e linhas teóricas vertentes da antropologia, e também da filosofia, serão lidas sempre em relação as palavras do xamã yanomami.
} 
com seres animados que inundam a floresta por todos os cantos. Irá se vislumbrar uma floresta mágica, com a sua multidão de seres em complexas relações, e assim se aproximar do tempo dos sonhos, que é o tempo xamânico por excelência. E as relações de Kopenawa com a floresta, e logo com os espíritos, influem diretamente na possibilidade da catástrofe ambiental que o xamã avista logo à frente para todos aqueles que habitam a terra, para todos aqueles que estão abaixo do céu.

A queda do céu que dá nome à obra, se refere à destruição da natureza que a existência do mundo branco vem causando, e que acabará por levar ao fim do mundo. E segundo Kopenawa (2016, p.497), os xamãs são aqueles que cooperam para sustentar o céu, para não permitir que o mundo acabe. Os brancos e os xamãs não se relacionam, não entendem a natureza da mesma forma, pois os brancos acreditam que a natureza está "morta", ou seja, que ela é apenas um conjunto árvores que logo se tornará livros ou mesmo que sua parte mais valiosa são os minérios que servem de matéria prima para suas mercadorias (KOPENAWA; ALBERT, 2016, p.409). Já o xamã sabe que a natureza está "viva", sabe que a floresta se encontra habitada por infinitos espíritos, e que estes espíritos são o que mantêm sua saúde, e logo são o que há de mais valioso nela (KOPENAWA; ALBERT, 2016, p.479). Enquanto para os brancos a pergunta; “O que é a natureza?” é óbvia. Para o xamã yanomami a pergunta óbvia parece ser; “Quem é a floresta?". Explorar e expor as diferenças destas duas posições forma a base deste artigo, que se constrói através da relação entre o mundo branco e o mundo yanomami.

A entropia ${ }^{4}$ é um conceito central para se entender a modernidade e seus diferentes fins do mundo, e como se irá ver, este conceito aparece sempre entre os ocidentais e suas especulações para o futuro do cosmos como um todo, e também mais especificamente, nas especulações sobre o futuro da espécie humana. As palavras do xamã parecem indicar um cenário fora da entropia para o futuro do cosmos, e é através da cosmologia apresentada no livro A queda do céu, e de seus personagens, que este artigo irá se aproximar do mundo xamânico. Já no final deste texto, irá se explorar a relação entre a entropia e a antropologia, através das palavras do clássico escritor Lévi-Strauss, que relacionou diretamente a

\footnotetext{
${ }^{4}$ A entropia será melhor explorada mais à frente, por enquanto é importante dizer que ela se refere basicamente a um processo de dissolução dos sistemas, um processo de "morte", um processo de desintegração.
} 
possibilidade de se combater a entropia com uma abertura de relação com os não-humanos que povoam o cosmos ${ }^{5}$.

\section{Os fins e os começos do mundo para os ocidentais}

Divididos entre política (humanos) e ontologia (natureza) estão à maioria e os mais conhecidos modos de pensar e de agir do ocidente (BENSUSAN, 2017, p.35). De um lado está a área do quem, e do outro a área do quê. De um lado estão todos aqueles que pensam, são animados, tem agência ${ }^{6}$; do outro lado está a natureza, tudo o que restou, o que está nos arredores, às margens do humano. O antropocentrismo é, primeiramente, o ato de colocar o humano no centro e, em seguida, a natureza para fora do centro, em seus contornos. Nesse sentido, a ontologia é disposta ao redor da política, dando-lhe um limite periférico (BENSUSAN, 2017, p.35). Separa-se a natureza do humano e, por consequência, separa-se a natureza daquilo que se torna exclusivamente humano. Essa exclusão, que é central para grande parte da tradição moderna escrita, se constitui por meio da possibilidade de uma natureza separável da política (BENSUSAN, 2017, p.37). Neste cenário a natureza se consolida enquanto um simples recurso para os humanos, como um cenário por onde os humanos desfilam sua superioridade.

A divisão dos lados ocorre também obedecendo a uma específica distribuição de poderes entre os polos, em um cenário no qual é dado ao humano o poder sobre a natureza (BENSUSAN, 2017 p. 34). Ou seja, a separação entre os lados não delega uma igualdade de poderes, mas constrói uma hierarquia, na qual o humano é o senhor e a natureza é a escrava. A natureza é aquilo que não tem poder sobre si mesmo, é heterodeterminada, pois segue leis já preestabelecidas. Os humanos, por sua vez, são aqueles que controlam seu próprio destino, são autodeterminados, criam as próprias leis (BENSUSAN, 2017, p.39). De um lado estão os humanos com a liberdade nas mãos, já do outro está à natureza enquanto elemento que obedece sempre ao mesmo ritmo, a mesma lei. Neste cenário, pode se perguntar, "quem são os humanos?", bem como "o que é a natureza?"

\footnotetext{
${ }^{5} \mathrm{O}$ antropólogo francês Lévi-Strauss será lido neste artigo, principalmente através dos caminhos que o filósofo Marco Valentim constrói na obra Extramundanidade e sobrenatureza.

${ }^{6}$ Nos debates atuais, a definição da palavra agência se aproxima à definição de individuo consciente, um agente consciente, ou seja, como aquilo que pode ser a fonte de uma ação, a origem de uma ação. "Atribuir agência a algo seria nesse sentido, atribuir mente ou intuição, não importa se a pessoas ou coisas" (SZTUTMAN, 2005, p.75).
} 
E também, pouquíssimas coisas pensam para a ciência ocidental e, assim, "quase nada" é alguém (humano) e, logo, "quase tudo" é apenas uma simples "coisa" (natureza). Por exemplo, de acordo com grande parte da ciência ocidental, no início dos tempos, logo após o Big Bang, apenas existia a natureza, e nada de humanos. De modo similar, no fim dos tempos, haverá também apenas a natureza, a matéria inerte, uma espécie de substância menos complexa que a humanidade (BENSUSAN, 2017, p.34). Os humanos, no meio da imensa duração do cosmos, surgiram de uma relação entre essas primeiras coisas naturais, que foram se complexificando com o tempo e acabaram por desembocar na humanidade. Então, em seu princípio, o cosmos científico moderno era feito apenas de pó estelar, ou seja, de partículas atômicas sujeitas às leis da natureza, que depois de muitos arranjos testados se tornaram o que viria a ser a cereja do bolo: o humano. A ciência, para explicar os primórdios dos humanos, precisa recorrer a uma natureza não humana, um cenário sem o humano a priori.

A duração da natureza é também várias vezes maior que a duração dos humanos neste cenário, onde a cosmologia é, muitas vezes, mais longa que a antropologia. Neste sentido, podemos dizer que o pensamento humano nasceu nos segundos finais da trajetória do cosmos, em um encontro feliz e único de suas partículas que ainda não tinham agência, mas passaram a ter, e, assim como surgiu de uma espécie de milagre - afinal, tal salto de evolução nunca mais foi visto - também sumirá de uma hora para outra. "O mundo começou sem o homem e terminará sem ele" (LÉVI-STRAUSS, 1996, p.391) é uma frase de Lévi-Strauss, escrita em Tristes trópicos, que resume bem o que grande parte da ciência ocidental pensa. A origem da espécie humana se deu em razão de circunstâncias extremamente específicas e raras, e também essa mesma humanidade apresenta uma vida frágil, que irá levar a uma rápida extinção, e, de certo modo, depois da morte da consciência (humana), o universo voltará a parecer incompleto, já órfão de seu filho mais complexo. O universo, após a breve passagem dos humanos, aparentará ser sozinho novamente.

Lévi-Strauss também afirma que o mundo terminará algum dia, o que está de acordo com a opinião de muito astrofísicos, que preveem um Big Crunch, enquanto resultado do princípio entrópico. Mas também existe uma vertente da ciência, o transhumanismo, representado por John Smart, Raymond Kurzweil, e James Garden, que apresenta uma saída para este fim catastrófico de tudo o que existe, e, como não poderia deixar de ser, a fuga da corrosão de tudo será através das inovações tecnológicas que os humanos poderão um dia construir, um dia nem tão distante assim (ROMANDINI, 2012a, p.122). Para estes autores, a humanidade será um dia capaz de construir uma tecnologia tão complexa, que outro universo 
poderá ser criado, e nele os futuros humanos poderão viver mesmo que o universo que hoje conhecemos acabe. De certo modo, é como se a humanidade fosse um dia ser capaz de criar outro Big Bang, mas agora através de uma expansão da inteligência e do pensamento por todo o universo, por intermédio da nanotecnologia, ou seja, é a utopia de uma espécie de invasão do cosmos por nanorrobôs minúsculos e infinitos, que criarão outros cosmos. Essa dispersão da tecnologia permitiria um "crescimento exponencial contínuo de complexidade e inteligência" (SMART, apud, ROMANDINI, 2012a, p.124), abrindo espaço para um novo universo inteligente futuro.

"A inteligência nanobiológica será bilhões de vezes mais poderosa, e, portanto, prevalecerá. Teremos corpos em versão 3.0, os quais poderemos modificar e reelaborar à vontade, segundo novas formas.” (KURZWEIL, apud, ROMANDINI, 2012a, p.121). O otimismo dessa linha científica é imenso, e a proposta é a de uma futura possibilidade de imortalidade do cosmos, junto também de uma imortalidade dos humanos, mediante o uso de uma nanotecnologia que preservará apenas a lógica cognitiva humana e se libertará do corpo animal perecível (ROMANDINI, 2012a, p.121). Entre as propostas desta vertente científica está, por exemplo, a troca de todos os órgãos humanos por peças feitas em laboratório com funcionamento mais eficiente - seriam então corações, pulmões e cérebros constituídos de nanorrobôs que otimizariam a vida humana e os tornariam imortais ao mesmo tempo. Já em 2030, os humanos seriam capazes de trocar as conexões neurais do cérebro por "conexões virtuais de alta velocidade por meio da comunicação nanorrobótica" (KURZWEIL, apud, ROMANDINI, 2012a, p.121). A ideia é basicamente trocar toda a matéria inerte do cosmos por uma tecnologia inteligente criada pelos humanos.

O movimento transhumanista é o exemplo ideal que Romandini utiliza para fundamentar uma regra que, para o filósofo, guia toda a ciência moderna: trata-se do princípio antrópico forte (ROMANDINI, 2012b, p.11), ou melhor, o finalismo antrópico forte. Este é um princípio que descentraliza a humanidade em um primeiro momento, pois, como visto, os humanos não estão no começo do universo para a ciência em geral, ou seja, os humanos não são um "fundamento propositivo" (ROMANDINI, 2012b, p.11), mas, paradoxalmente, esse passo vem acompanhado de uma humanidade vista enquanto um fim do processo cósmico, vista como uma espécie de fim necessário ${ }^{7}$. É o princípio que marca a humanidade como a apoteose

\footnotetext{
${ }^{7}$ Nos transhumanistas está mais claro o princípio antrópico, mas mesmo quando a ciência propõe que o humano irá se extinguir, essa humanidade se mantém, de certa forma, "um fim", pois o surgimento do humano
} 
do universo. Neste sentido, por exemplo, vários físicos acreditam que desde o Big Bang, todas as relações que o universo teve que traçar para se desenvolver, já estariam direcionadas necessariamente por "leis naturais" programadas para a produção da humanidade, por exemplo, essa visão defende que, se qualquer das leis físicas tivesse sido alterada, por acaso, em seu desenvolvimento, ou seja, se a água tivesse virado carbono por um acaso, ou se algum gás da atmosfera fosse diferente do que é hoje, ou se o movimento dos planetas fosse em outra velocidade e intensidade, a espécie humana não estaria aqui para contar história.

Há de se pensar agora, na religião cristã, na frase "do pó viemos, e ao pó voltaremos" (BÍBLIA, Gênesis, 3, 19), onde se resume um dos dogmas de tal conhecimento, que se aproxima muito das palavras de Lévi-Strauss já citadas, pois ambas reafirmam a intuição de que a origem e o destino dos humanos é a natureza. Na Bíblia está escrito que no início dos tempos houve a construção do mundo, feita por Deus com todo o cuidado, para depois ser entregue nas mãos de sua criação mais importante. Dessa forma, o mundo foi construído sem os humanos, mas ao mesmo tempo, também foi feito para os humanos (DANOWSKI; VIVEIROS DE CASTRO, 2014, p.37). O Éden, neste sentido, representa a aurora do cosmos como a ideia de espaço ainda não corrompido pelas intenções negativas humanas, um mundo ainda sem pensamento, sem os espíritos, sem o poder de escolha, sem a autonomia da decisão, sem o pecado. Essa ideia de um mundo equilibrado, inesgotável, em um eterno movimento de criação e destruição, em um eterno movimento de vida e morte, continua até hoje nos interstícios do ocidente, enquanto o humano é visto como contra a natureza, como antinatural, desequilibrante, como algo que destrói mais do que cria (DANOWSKI; VIVEIROS DE CASTRO, 2014, p.37).

Outra figura moderna que se pode pensar como uma representante da ideia de dualidade entre a natureza (positiva) e a humanidade (negativa) é o apocalipse criado por Walter Benjamin na obra Teses sobre conceito de História. O filósofo cria uma imagem do fim do mundo onde também os humanos se mostram com um período curto de vida, prestes a sumirem do universo. É uma leitura do humano enquanto uma espécie de filho maldito do cosmos, é a humanidade enquanto catástrofe. As palavras do filósofo são:

Existe um quadro de Klee intitulado "Angelus Novus". Nele está representado um anjo, que parece estar a ponto de afastar-se de algo em que crava seu olhar. Seus olhos estão arregalados, sua boca está aberta e suas asas estão estiradas. O anjo da história tem de parecer assim. Ele tem seu rosto voltado para o passado. Onde uma cadeia de eventos aparece diante de nós, ele enxerga uma única catástrofe, que sem cessar amontoa escombros sobre escombros e os arremessa a seus pés. Ele bem que gostaria

se mantém o ponto alto da história do cosmos. O humano é aquilo mais complexo que pode ser criado, e depois da extinção humana, o cosmos não será mais grande coisa. 
de demorar-se, de despertar os mortos e juntar os destroços. Mas do paraíso sopra uma tempestade que se emaranhou em suas asas e é tão forte que o anjo não pode mais fechá-las. Essa tempestade o impele irresistivelmente para o futuro, para o qual dá as costas, enquanto o amontoado de escombros diante dele cresce até o céu. O que nós chamamos de progresso é essa tempestade (BENJAMIN, apud, LÖWY, 2005, p. 87).

A tese, já tão discutida, merece atenção por ser um grande resumo da crise ocidental (LÖWY, 2005, p.87), para esta vertente filosófica. Nela, teologia e política se entrelaçam, e, para cada figura profana, Benjamin identifica uma figura sagrada, por exemplo, o anjo (sagrado) é o sujeito histórico (profano), assim como o progresso é a tempestade que expulsa do paraíso ${ }^{8}$, e também o Éden é a representação dos povos não modernos, os quais, para o filósofo, como um bom romântico, ainda viviam em um comunismo sem distinção de classes (LÖWY, 2005, p.90). O retorno ao pó também está explícito na tese, pois a figura coloca a humanidade com os dias contados devido ao seu caráter destruidor, um caráter negativo que leva a humanidade a uma implosão.

Na obra $O$ Aberto, o filósofo Giorgio Agamben analisa a visão apocalíptica de Ezequiel, a qual apresenta uma representação do último dia da história dos judeus, ou melhor, o último dia da história humana para os judeus. O último dia, nessa visão, consiste no julgamento final que definirá o futuro dos humanos justos e dos injustos, e é o dia no qual o mistério da vida eterna será finalmente resolvido, ou seja, quando o reino dos céus é alcançado por alguns. $O$ fato de que somente alguns alcancem o céu é de extrema importância para a lógica apocalíptica. $\mathrm{Na}$ imagem de Ezequiel do dia após o fim, se revela outra coisa no lugar da existência de uma espécie humana por toda a eternidade, outra coisa no lugar de humanos vivendo no céu, pois nela estão os justos sentados à mesa, ou seja, aqueles que já passaram pelo julgamento, e eles não são totalmente humanos - são meio-humanos, e meio nãohumanos/animais/além-humanos - a figura apresenta a imagem de homens-animais, ou então animais-homens, que serão os habitantes da eternidade (AGAMBEN, 2011, p.10).

São desenhos que mostram que os justos, apesar de terem um corpo humano, possuem também uma cabeça de animal, o que faz o filósofo propor uma leitura na qual a humanidade é tida como uma espécie de negativo, que está destinado a se reconciliar com a natureza com o tempo, e assim a sumir no futuro, como que se diluindo pela natureza novamente (AGAMBEN, 2011, p.12). É como um negativo englobado por um processo dialético, simples, que acaba

\footnotetext{
${ }^{8}$ Um ponto importante de se notar é que Benjamin ainda está desavisado das questões climáticas, pois a obra é do ano de 1940, quando a ecologia ainda não era uma palavra do vocabulário da escola alemã de filosofia. Assim, não é o céu que está prestes a cair, mas sim a acumulação humana, o progresso que está em vias de ultrapassar o céu.
} 
gerando como resultado uma união da humanidade com a natureza. Sendo assim, no último dia, a fronteira que antes separava os humanos dos animais acaba, e os dois lados se fundem, de forma que uma estranha teriomorfia (AGAMBEN, 2011, p.12) se apresenta no juízo final, tornando a vida eterna só possível com o fim da vida humana, ou melhor, com o fim de uma vida só humana. É como se a imagem falasse: "No céu não teremos almas puramente humanas!”. Esta versão apocalíptica parece se encaixar perfeitamente na tradição que entende o humano como um negativo e a natureza como positiva, e, nesse caso, a natureza se mostra tão positiva, a ponto de um dia poder eliminar, ultrapassar a contradição humana. $\mathrm{O}$ humano até estará no céu, mas não será mais puramente humano.

Para terminar a exposição dos possíveis "fins" no ocidente, temos ainda os argumentos de Tomás de Aquino. Para o teólogo, a humanidade também se mostra um negativo, mas em outro sentido, pois, ao contrário do cenário analisado por Agamben, no céu apenas existirão os humanos, pois todo o resto será destruído pela humanidade que triunfa sozinha no reino do céu, "logo, as plantas e os animais desaparecerão inteiramente depois da renovação do mundo" (AQUINO, apud, VALENTIM, 2018, p.268). Para esta linha cristã, será o homem que irá dominar o reino dos ressuscitados plenamente e absolutamente, finalmente liberto de sua mortalidade "animal", e também liberto de toda biodiversidade que o planeta hoje apresenta. Essa versão se aproxima muito da ideia dos cientistas transhumanistas, pois, em ambos os casos, o que está em cena é um futuro só humano. Como Romandini observa, essa lógica hoje aparece secularizada e absorvida pelas políticas ambientais dos estados modernos, que caminham a passos largos na extinção de várias espécies não-humanas do planeta. A negatividade da humanidade, neste caso, prevalece sobre todas as demais espécies que formam o planeta, e projetam um pós-universo sem a natureza, e, por consequência, só humano (ROMANDINI, 2012a, p.188).

\section{O fim e o começo do mundo xamânico}

Se o ocidente diz que tudo começou sem os humanos e vai terminar também sem os humanos $^{9}$, ou então que no fim só existirão os humanos, o xamanismo indica outro cenário. Nos primórdios do tempo "ainda não havia nada, mas já existiam as pessoas” (DANOWSKI, VIVEIROS DE CASTRO, 2014, p.87), como resume a frase do mito Yawanawá. O que esta frase diz é uma inversão da relação ocidental, pois o humano é colocado como anterior à

\footnotetext{
${ }^{9}$ A teriomorfia analisada por Agamben, é uma exceção à regra e, como visto, marca uma humanidade e uma animalidade juntas após o fim do mundo.
} 
natureza e, sendo assim, a natureza não aparece como figura constituinte do humano, ou seja, como aquilo que dá origem à humanidade, mas o contrário acontece. Para os ameríndios, foi a humanidade que chegou primeiro, e assim existe uma "impensabilidade de um mundo sem gente" (DANOWSKI; VIVEIROS DE CASTRO, 2014, p.106), seja no passado ou no futuro. Neste sentido, a humanidade é vista enquanto a matéria primordial, a partir de onde o mundo veio a ser formado (DANOWSKI; VIVEIROS DE CASTRO, 2014, p.87).

Para os ameríndios, a ideia de uma extinção definitiva da raça humana no fim dos tempos também não é comum. Tampouco é comum a ideia de um triunfo só dos humanos, pois o xamanismo pode pensar no fim dos humanos que hoje existem, mas isso não significa o mesmo que pensar no fim da humanidade enquanto tal, e sim apenas no fim de uma humanidade específica (DANOWSKI; VIVEIROS DE CASTRO, 2014, p.106) e, ademais, o xamanismo diz que depois da queda do céu “outras gentes” (KOPENAWA; ALBERT, 2016, p.497) virão a existir, "gentes" humanas e também "gentes" além dos humanos, gentes "não-humanas". É importante ressaltar que muitos seres além dos humanos também virão a existir após a queda do céu para o xamanismo, sejam os infinitos espíritos, os animais, ou até mesmo a floresta como um todo (KOPENAWA; ALBERT, 2016, p.497). Um modo de ver essa questão das diversas humanidades, é que, por exemplo, para Kopenawa, os yanõmami tëpë (os seres humanos de hoje) são como uma terceira espécie humana, pois já existiu uma primeira humanidade, në pata pë, soterrada devido a uma antiga queda do céu, e depois uma segunda humanidade que sumiu em um dilúvio, para então, finalmente, acontecer a chegada dos humanos de hoje (LEITE, 2010, p.41).

A humanidade, de certo modo, é vista como múltipla, e cada humanidade tem suas características peculiares (KOPENAWA, ALBERT, 2016, p.117) e, assim como já existiram diferente espécies humanas, o futuro se mostra também cheio de "gente". Após a queda do céu, existirão também outros seres para além dos humanos, ou seja, outras floresta irão existir, povoadas com outros seres. A questão é que não é um retorno ao pó - algo que, por consequência, eliminaria qualquer possibilidade de uma futura espécie humana - o que assombra o xamanismo, mas sim a possibilidade de um "retorno ao caos" (KOPENAWA; ALBERT, 2016, p.493). Como escreve o xamã:

"No primeiro tempo todos fazíamos parte da mesma gente. As antas, os queixadas, e as araras que caçamos eram humanos". "No início o céu ainda era novo e frágil, a floresta era recém-chegada à existência e tudo nela retornava facilmente ao caos. Moravam nela outras gentes, criadas antes de nós, que desapareceram". "Mais tarde, se não houver mais xamãs na floresta para e segurar, vou cair de novo sobre a terra, como no primeiro tempo! Mas dessa vez vou fazer viver em minhas costas gentes 
diferentes desses brancos [...] pode ser que, depois de muito tempo, outras gentes venham a existir em nosso lugar" (KOPENAWA; ALBERT, 2016, p.473, 195, 497).

O mundo sempre teve gente, gentes, agência, consciência, e até mesmo antes do mundo já existia gente, é isso o que parece propor o xamã. Essa possibilidade é explorada por Kopenawa e por outras várias escatologias ameríndias já coletadas por diferentes antropólogos (DANOWSKI; VIVEIROS DE CASTRO, 2014, p.87). Nos primórdios dos tempos, portanto, o xamã não nos diz que nada era humano, mas sim que tudo era humano, ou melhor, "que nada não era humano" (DANOWSKI; VIVEIROS DE CASTRO, 2014, p.87). Se para a ciência moderna de forma geral o mundo começou sem gente, para o xamã ele começou cheio de gente, ou melhor, no início também existia gente, e não apenas uma natureza pura. Dessa humanidade tudo o que existe hoje surgiu, até o que os brancos chamam de natureza. Em vez da questão "o que estava no começo?”, se encaixa melhor a questão “quem estava no começo?”.

O passado xamânico não é não-biótico, não-mental, mas sim estranhamente hiperpovoado por vários seres que "eram humanos" (KOPENAWA; ALBERT, 2016, p.473), mas não humanos como nós (modernos) acreditamos ser, pois os ameríndios são outros e, consequentemente, os humanos deles também são outros (DANOWSKI; VIVEIROS DE CASTRO, 2014, p.33). Esta humanidade primordial, que estava lá no começo de tudo, era instável e estava sempre se transformando em animal, sempre se transformando em outro (KOPENAWA, ALBERT, 2016, p.614). Era uma humanidade, como Albert escreve, que estava inclinada ao "devir animal” (yaroprai) (KOPENAWA; ALBERT, 2016, p.614). Eram seres que não eram totalmente humanos, mas também não eram totalmente não-humanos. Eles "eram humanos com nomes de animais e não paravam de se transformar" (KOPENAWA; ALBERT, 2016, p.81), chamados de yaro hi, que seriam os antepassados tanto dos humanos quanto dos animais de hoje em dia (KOPENAWA; ALBERT, 2016, p.614). No primeiro tempo, existiam os humanos-queixadas, humanos-veados, humanos-cutias, diz o xamã yanomami (KOPENAWA; ALBERT, 2016, p.195).

Esta humanidade primordial que é exposta nas cosmologias Yanomami não é a "espécie humana" como imaginada pelos modernos, não é a espécie "natural” humana, "mas a condição social da pessoa” (VIVEIROS DE CASTRO, 1996, p.125). Os ameríndios dizem que já existia muita "gente", por que "gente" não se refere apenas a "espécie humana", mas também se refere a outros não-humanos com intencionalidade, com consciência, com agência. A palavra "gente" significa "pessoa" no contexto ameríndio, e se refere aos humanos e também aos nãohumanos que tem “intencionalidade consciente" (VIVEIROS DE CASTRO, 1996, p.126). Nas 
cosmologias ameríndias, os não-humanos também tem a capacidade intencional características dos humanos na modernidade, os não-humanos também tem "alma", também tem "espirito" (VIVEIROS DE CASTRO, 1996, p.126). É interessante notar que os “animais ancestrais” que existiam já no começo dos tempos, continuam a existir de certo modo, mas não exatamente como eram antes, pois agora estão separados entre a pele, que veio a se tornar os animais de caça, e o interior que se tornou os xapiri, os espíritos, os quais estão dispersos por toda floresta (KOPENAWA; ALBERT, 2016, p.117).

Pode-se dizer então que a humanidade está presente desde o começo, ou mesmo antes do começo, e que esta mesma humanidade, de certa forma, continua hoje como um fundo de todo o cosmos na forma de espíritos que ainda carregam uma parte humana em sua constituição. É importante notar que essa humanidade primeira, mais do que ser totalmente humana, é também humana, ou melhor, não é totalmente não-humana (VALENTIM, 2018, p.195). Em vez de um mundo sem os humanos, tem-se humanos sem o mundo, ou então humanos-mundo, um mundo, portanto, excessivamente humano, em detrimento do humano enquanto exceção.

No início havia muita gente, e depois do fim, também existirá muita gente, humana e também não-humana. A ideia de extinção da raça humana é vista de um modo diferente dos modernos. Enquanto no ocidente normalmente tem-se a ideia de que primeiro acabam os humanos e depois o mundo, para os ameríndios parece haver uma relação direta entre estes dois, uma relação mesmo de sobrevivência. O fim do mundo é um fim para a humanidade e vice-versa (DANOWSKI; VIVEIROS DE CASTRO, 2014, p.110). Ademais, a esta constatação soma-se, também, que a recriação do mundo é a recriação de alguma forma de humanidade, de consciência (DANOWSKI; VIVEIROS DE CASTRO, 2014, p.110). A ideia de que o mundo acabará de uma vez por todas é estranha às cosmologias ameríndias. Após o fim do mundo, haverá outro mundo-humanidade, e esse novo mundo-humanidade passará por outro fim do mundo, e assim por diante. O novo mundo não é uma hiperestrutura nanorrobótica, e muito menos uma criação dos humanos brancos, pois o novo universo já está incluído na lógica do cosmos. Em suma, existe uma "consubstancialidade entre humanidade e mundo" (DANOWSKI; VIVEIROS DE CASTRO, 2014, p.110). Além disso, ao contrário da corrente transhumanista e das profecias de Tomás de Aquino, o futuro não é só humano, e muito menos só de humanos brancos, pois existirão todos os demais seres que formam o cosmos, humanos e não-humanos, e, na verdade, segundo o xamã, são os humanos brancos, exatamente aqueles que vão sumir. 
A questão dos vários fins do mundo explicada por meio da figura da queda do céu por Kopenawa não é exclusiva do xamã, e também não é exclusiva dos yanomamis, pois muitas outras escatologias de povos ameríndios expressam ideias parecidas (DANOWSKI, VIVEIROS DE CASTRO, 2014, p.102). Nessas escatologias é comum ver o cosmos em um movimento contínuo de rearranjo, de forma que as camadas de "terra" e de "céu" estão sempre se sobrepondo uma sobre a outra, em um movimento de cascata, de maneira que uma série de planos empilhados correm uns sobre os outros trocando de lugar por várias causas possíveis (DANOWSKI; VIVEIROS DE CASTRO, 2014, p.101). Os diferentes fins do mundo se desencadeiam de várias formas como, por exemplo, devido ao excesso de mortes que deixa o céu muito pesado (KOHN, 2012, p.218), ou mesmo um excesso de almas na terra, existem casos nos quais dilúvios varrem a terra; em outros, incêndios gigantes tomam conta de toda a floresta (DANOWSKI; VIVEIROS DE CASTRO, 2014, p.101). Há narrações em que deuses míticos descem do céu e devoram tudo o que veem pela frente devido aos comportamentos desregulados dos humanos que a habitam. (NIMUENDAJU, apud, DANOWSKI; VIVEIROS DE CASTRO, 2014, p.102).

As costas do céu que caiu no primeiro tempo tornaram-se a floresta em que vivemos, o chão no qual pisamos. Por esse motivo chamamos a floresta wãro patarima mosi, o velho céu, os xamãs também a chamam de Hutukara que é mais um nome desse antigo nível celeste. Depois um antigo céu desceu e se fixou acima da terra, substituindo o que tinha desabado. Foi Omama, que fez o projeto, como dizem os brancos (KOPENAWA; ALBERT, 2016, p.195).

Nesse movimento de consecutivas quedas, aquilo que era o céu de ontem será a terra de amanhã, e a terra de hoje será uma camada subterrânea do solo de amanhã, e assim sucessivamente. “O céu se move, é sempre instável” (KOPENAWA; ALBERT, 2016, p.196) e “continua instável e frágil” (KOPENAWA; ALBERT, 2016, p.197). Kopenawa afirma que atualmente o centro do céu ainda está firme, mas que "suas beiradas já estão bastante frágeis" (KOPENAWA; ALBERT, 2016, p.197), o que aponta para uma possível nova queda (VALENTIM, 2018, p.284). Nesse movimento incessante do cosmos, a humanidade é sempre renovada em um cenário no qual os humanos de hoje são jogados para baixo da terra e se tornam seres intraterrestres canibais, seres como os "ã̃apataripë - criaturas subterrâneas, canibais, resultantes do soterramento da primeira humanidade pela queda do céu" (KOPENAWA; ALBERT, apud, LEITE, 2010, p.53). E os seres que estavam acima do céu tornam-se os humanos do amanhã. Isso já aconteceu no passado, e pode voltar a acontecer no futuro, diz Kopenawa (KOPENAWA; ALBERT, 2016, p.497). “Os brancos não temem, como nós, ser 
esmagados pela queda do céu. Mas um dia eles terão medo, talvez tanto quanto nós!" (KOPENAWA; ALBERT, 2016, p.484).

\section{A floresta xamânica}

A aproximação mais simples possível da palavra "floresta", que é constantemente usada por Kopenawa (2016, p.475), é aquela que a identifica e a traduz enquanto ao que os modernos chamam de natureza. Essa tradução bruta esconde problemas que a antropologia contemporânea não cessa em questionar ${ }^{10}$, e Kopenawa (2016) ajuda a complexificar essa aproximação súbita. O xamã diz que aquilo que os modernos, os napës (brancos), chamam de natureza, na língua yanomami carrega dois principais sinônimos (KOPENAWA; ALBERT, 2016, p.475). Então, a palavra natureza pode ser traduzida enquanto Urihi, a terra-floresta, que é visível aos napës, aos índios não-xamãs e também aos xamãs. Essa parte da floresta são as árvores, os animais, as pedras, tudo aquilo que se vê normalmente em um estado não xamânico, em um estado ordinário de percepção, é a natureza ordinária. A "natureza” é também formada por outra parte, a Urihinari, o espírito ${ }^{11}$ da floresta, uma "imagem, visível apenas aos xamãs" (KOPENAWA; ALBERT, 2016, p.475), que está sobreposta/junta/inseparável de tudo o que existe na floresta, nas árvores, animais, na chuva, em tudo, é o sobrenatural.

Essa camada sobrenatural é principalmente acessada através dos estados alterados de percepção alcançados mediante da ingestão de yãkoana, que abre o tempo dos sonhos, o tempo dos espíritos. A yãkoana é a substância em forma de pó conseguida por meio de complexos processos de preparação, que envolvem a mistura de diferentes plantas da floresta. Basicamente, no entanto, o pó é fabricado com a seiva da árvore Virola Elongata, que contém altos níveis da substância dimetiltripitamina (DMT) (KOPENAWA; ALBERT, 2016, p.612). A ingestão contínua da yãkoana em altas doses, por vários dias, é um pré-requisito para se aprender no xamanismo, para se tornar um xamã. Segundo as palavras do xamã:

Nós, yanomami, que somos xamãs, vemos-conhecemos (taai,-). Vemos a floresta. Depois de tomar o poder alucinógeno de suas árvores, nós vemos. Fazemos os espíritos da floresta, os espíritos xamânicos, dançarem suas danças de apresentação. Vemos com nossos olhos. Depois de 'morrer' sob o poder do alucinógeno, vemos a 'imagem essencial' da floresta. Vemos o céu sobrenatural! (ALBERT, 2002, p. 249).

\footnotetext{
${ }^{10}$ São diferentes antropólogos que estão ligados a multiplicação da natureza, dentre eles, Viveiros de Castro, Philippe Descola, Renato Sztutman, entre outros.

${ }^{11}$ Existe o interessante filme "Xapiri", dirigido por; Leandro Lima, Gisele Motta, Laymert Garcia, Stella Senta e Bruce Albert, onde se busca mostrar as visões que os xamãs alcançam após alterarem a consciência através da yãkoana.
} 
Praticar o xamanismo é xapirimuu ("agir em espírito"), enquanto se tornar xamã é xapiripruu ("torna-se espírito") (KOPENAWA; ALBERT, 2016, p.610). Ao se tornar xamã, Kopenawa se tornou um espírito, diz ele próprio no capítulo "A iniciação" que detalha os passos de sua exaustiva formação, com seu sogro, o xamã Lourival: Kopenawa diz ao fim da iniciação, "eu mesmo tinha me tornado um deles" (KOPENAWA; ALBERT, 2016, p.149), um espírito. Ao "agir/entrar em estado de fantasma" (рогетии)" (KOPENAWA; ALBERT, 2016, p.615), após "morrer" sob a influência do psicoativo, os xamãs têm acesso a utupë, uma "imagem corporal/essência vital" (KOPENAWA; ALBERT, 2016, p.626) que todo ser da floresta carrega consigo mesmo, uma espécie de "interior/essência vital dos seres animados atuais" (KOPENAWA; ALBERT, 2016, p.615). De um modo simples de explicar, a utupë é uma espécie de forma, com suas próprias características, que tudo e todos que existem apresentam em uma realidade sincrônica, em uma realidade paralela à nossa, (SÁEZ, 2006, p.370), mais exatamente na realidade do tempo dos sonhos. Os xamãs são então os responsáveis por fazer descer do "céu sobrenatural" (ALBERT, 2002, p.249) as imagens utupë, que estão nos "seres, entidades, e objetos dos mais diversos" (KOPENAWA; ALBERT, 2002, p.622). Estão em todos os tipos de animais, como peixes, pássaros e insetos, e também estão nas árvores, na terra, nas folhas, na água, nas nuvens, na lua, entre outros “objetos", "dos mais domésticos (cão, fogo, cerâmica) aos mais exóticos (ancestrais dos estrangeiros/brancos, dos bois, cavalos, carneiro)" (KOPENAWA; ALBERT, 2016, p.622).

Então segundo o xamã yanomami, o que os modernos chamam de natureza é apenas uma parte do que os xamãs consideram uma floresta. A parte mais importante é justamente a que os napës não têm acesso. Desse ângulo, traduzir floresta como natureza é perder uma grande parte do significado da questão, a parte mais importante aliás. São “os espíritos xapiri os verdadeiros donos da floresta, e não os humanos" (KOPENAWA; ALBERT, 2016, p.475). Os espíritos são aqueles que os napës não veem e que dão vida a tudo o que está ali, mas que passam imperceptíveis para os olhos não treinados através do xamanismo. A floresta que o xamã conhece tem algo além da natureza conhecida pelos não-xamãs. Por isso, acredito ser interessante investir no nome sobrenatural.

Diferente da hipervalorização da cultura sobre a natureza, tão comum no ocidente, o que se tem nas visões xamânicas é bem diferente. Vê-se uma região sobrenatural, extranatural, com propriedades e características ao mesmo tempo próximas ao que o moderno pensa ser uma natureza e uma cultura, o que acaba impedindo o passo básico do moderno de supervalorizar um em vez do outro. Na verdade, tudo se passa como se existisse um terceiro termo, a 
sobrenatureza, que parece estar tão acima da sociedade quanto a sociedade está acima da natureza (LÉVI-STRAUSS, 2013, p.354). Como a floresta pensa, ela não é exatamente uma natureza, ou seja, ela não é apenas feita de árvores, mas está povoada de canto a canto de seres, espíritos, espectros. A floresta não é exatamente só uma sociedade (moderna) também, já que possui mais que humanos em sua constituição.

Então, por isso, é importante chamar a floresta, a "natureza xamânica", de outro nome que não apenas natureza, seja sobrenatureza, seja extra-natureza. A ideia é pensar essa supervisão do xamã como uma espécie de terceiro termo. Pensamos o sobrenatural nesse artigo no sentido de algo visto apenas pelo xamã sobre o que os napës chamam de natureza. Então, parte do presente trabalho investe em uma reinserção da palavra sobrenatural (extranatural/além-natural/supernatural) nos debates antropológicos. Assim, o próprio conceito de natureza sofre adição de uma camada extra, que serve para destacar a cegueira do olhar dos brancos, apontada pelo xamã Davi Kopenawa.

\section{O ser do caos (não-humano)}

“Omama enterrou o metal junto ao ser do caos Xiwãripo [...] Se os Brancos de hoje conseguirem arrancá-los com suas bombas e grandes máquinas, do mesmo modo que abriram a estrada em nossa floresta, a terra se rasgará e todos os seus habitantes cairão no mundo de baixo" (KOPENAWA; ALBERT, 2016, p.359). Para o xamã, o retorno ao caos é o destino que os brancos estão implicando, empurrando, forçando a todos os outros seres - humanos e nãohumanos - que existem. Como o xamã diz, são os brancos que estão a ponto de rasgar a terra de tal modo que o movimento de cascata será reatualizado pelo ser do caos - mas o que, ou melhor, quem é o ser do caos? Um modo de começar a responder esta questão é indo até o vocabulário yanomami. Existe uma expressão xi wãri, que se refere a um estado/ação/influência que pode acontecer com qualquer dos seres da floresta (KOPENAWA; ALBERT, 2016, p.616), com o próprio "espírito da floresta", com os índios não-xamãs e com os xamãs. A expressão pode ser traduzida como "metamorfosear-se, perder a própria forma, retornar ao caos [...] perder o juízo, estar fora de si” (KOPENAWA; ALBERT, 2016, p.616), diz Bruce Albert. A expressão xi wãri tem um sinônimo, que é në ai pëi, "tornar se outro, assumir outro valor [...] enredar-se, tornar-se inextricável" (KOPENAWA; ALBERT, 2016, p.616), ao que parece o caos é uma possibilidade de se precipitar em um hiper desequilíbrio momentâneo, que, no caso de atingir o cosmos, se mostra capaz de extinguir tudo o que está acima da terra e abaixo do céu. É como se o horizonte terrestre pudesse perder sua linha por um instante, o que acaba por levar a um 
reposicionamento da cascata cósmica, que se atualiza, transformando o que era céu em terra, o que era terra em intraterrestre, e assim sucessivamente.

"A floresta é inteligente, ela tem um pensamento igual ao nosso. Por isso ela sabe se defender com seus xapiri e seus seres maléficos. Ela só não retorna ao caos porque alguns xamãs ainda fazem dançar seus espíritos para protegê-la.” (KOPENAWA; ALBERT, 2016, p.497). Kopenawa observa que são os xamãs os responsáveis por não deixar o caos se reinstaurar. Os xamãs também viram fantasmas ${ }^{12}$ com a ingestão de yãkoana para contemplar a imagem dos seres no tempo dos sonhos (KOPENAWA; ALBERT, 2016, p.140), os xamãs são, mais precisamente, os mestres no exercício de virar espírito. Após virar espirito através da alteração de consciência com a ingestão do psicoativo yãkoana, e assim entrar no tempo dos sonhos, junto com os outros espíritos, inclusive junto com Omama, o xamã ajuda na troca da imagem (utupë) de hutukara, e este processo de trocar a imagem é o que mantém o cosmos como ele está hoje em dia. A ação dos brancos força os cosmos a se reatualizar, entrando em uma transformação que altera os patamares celestes, enquanto a ação dos xamãs e de todos os outros espíritos, inclusive os espíritos maléficos, contém, e resiste à reatualização das camadas celestes.

Nas palavras do xamã: "quando acham que sua terra está ficando doente, os brancos falam de poluição. Quando a doença se alastra em nossa floresta, dizemos que está tomada por fumaças de epidemia, e que entrou em estado fantasma.” (KOPENAWA; ALBERT, 2016, p.478). Como visto, tudo pode entrar em estado fantasma, mas o xamã é aquele que tem maior controle sobre esse processo, é como se os xamãs pudessem entrar em "estado espírito" para controlar outros estados espectrais incontroláveis. Sendo assim, que o cosmos entre em estado fantasma é um problema causado pelos brancos, mas o xamã entrar em estado fantasma é uma solução e um pré-requisito para ser xamã. O xamanismo é uma espécie de exercício que pode controlar, através dos espíritos (não-humanos) e com eles, a intensidade destruidora exacerbada da civilização dos brancos, que polui os rios, o ar e a terra por onde passa, evitando, assim, que o céu, induzido ao estado fantasma, caia na cabeça dos humanos (KOPENAWA; ALBERT, 2016, p.496). Os xamãs não tratam os não humanos, a natureza em geral, apenas enquanto um

\footnotetext{
12 "Virar fantasma” (poremuu) é o estado de alteração da consciência alcançado com a yãkoana, e a palavra fantasma também é usada no livro para se referir a possibilidade do cosmos entrar em estado fantasma, e assim a cascata cósmica é atualizada. Existe ainda a expressão "olhos fantasmas", que se refere ao modo enganoso através do qual os não-xamãs veem o mundo, pois não podem ver o mundo invisível. Tudo pode "virar fantasma", como Valentim diz (VALENTIM, 2018, p.229), desde dos espíritos, aos xamãs, a floresta, aos não xamãs.
} 
recurso inesgotável a serviço dos desejos humanos; a floresta para o xamã não é "morta" e escrava das leis da natureza, pois ela está inundada de espíritos, que trabalham junto com os xamãs para que ela permaneça como é.

\begin{abstract}
Xiwãripo é o mundo que está mudando, o que vocês não índios chamam de mudança climática. Vocês falam de mudança climática, na televisão falam que o clima do mundo está mudando, que está muito quente. Isso porque vocês estão acabando com a floresta. Então, a gente tenta acalmar ele. Está esquentando muito porque ele está bravo com você (KOPENAWA; GOMES, 2015, p.152).
\end{abstract}

Uma das possíveis conclusões que estes ensinamentos do xamã propõem é que a atividade de dissipação do calor que o branco faz no mundo visível ${ }^{13}$ reverbera pelo mundo invisível enquanto raiva, ira, que é conhecida apenas pelos xamãs, o que acaba gerando uma guerra no sobrenatural, uma guerra dos espíritos contra a ação desmedida dos brancos. É como se a ação dos brancos no mundo visível gerasse consequências no mundo invisível, e como também se os brancos não pudessem calculá-las. É importante dizer que esta guerra no sobrenatural volta a causar consequências na natureza visível, na natureza ordinária, como, por exemplo, a queima da floresta, ou sua perda da fertilidade (KOPENAWA; ALBERT, 2016, p.207). A destruição branca alcança assim uma reversibilidade entre o mundo invisível (dos espíritos) e o mundo visível.

O ser do caos é o Xiwãripo, que, junto com vários outros seres, serão os articuladores da fúria vingativa que irá levar o universo à catástrofe, e, no tempo dos sonhos, eles dizem aos xamãs: "Por mais que os brancos acreditem que possam aumentar sem limites, vamos colocálos à prova! Veremos se são tão poderosos quanto pensam! Vamos mergulhá-los na escuridão e na tempestade!" (KOPENAWA; ALBERT, 2016, p.494). O xamã diz que a ação do branco destruirá o "vento fresco da floresta” (KOPENAWA; ALBERT, 2016, p.361) que protege tudo aquilo que existe, sejam as árvores, os rios, os yanomami, ou até mesmo os xapiri, e assim o “calor” (KOPENAWA; ALBERT, 2016, p.361) se espalhará por todos os cantos, pois "essas coisas caídas do primeiro céu são muito quentes (minérios). Se forem todas expostas a descoberto, incendiarão a terra" (KOPENAWA; ALBERT, 2016, p.360). A terra, então, em seus patamares mais baixos contém um tipo de hiper calor, que é contido de se alastrar pela ação dos seres da floresta, a qual funciona como uma "geladeira de vacinas" (KOPENAWA; ALBERT,

\footnotetext{
${ }^{13} \mathrm{O}$ xamã, basicamente, tem acesso a dois mundos: o mundo visível, ordinário, o mundo que todos têm acesso; e também o mundo invisível, o mundo encanto, o mundo dos espíritos, que apenas os xamãs têm acesso.
} 
2016, p.360), que então impede esse calor de alcançar muita intensidade, o que geraria como resultado o caos.

É importante notar que as palavras do xamã yanomami se aproximam muito do conceito geológico do antropoceno ${ }^{14}$. Enquanto os sonhos modernos expressam uma natureza servil, uma natureza sobrecontrolada, uma natureza em segundo plano, o que vem acontecendo é que a sensação de insatisfação de tudo aquilo que restou do lado natural só aumenta. Se a natureza já foi tratada como um plano de fundo, repentinamente ela se tornou uma protagonista descontrolada que se sobressai e não se permite mais ser excluída, enquanto paisagem muda e constante (STENGERS, 2015, p.42). O antropoceno é o início de um período geológico no qual os humanos têm influência decisiva em sua origem. Esse novo período diz que não mais se enfrenta uma natureza pura, mas sempre uma conexão entre os humanos e o resto, um cenário no qual a diferença entre cosmologia e antropologia se mostra borrada, pois ao que tudo indica "os seres humanos, em outros termos, se tornaram atualmente uma força natural" (CHAKRABARTY, 2013, p.17). Depara-se, então, com espécies de forças geoantropicas. As palavras do xamã vão ao encontro deste conceito do ocidente, e apontam para uma catástrofe ambiental futura na qual os humanos (brancos) tem uma participação decisiva. As palavras do xamã além de descreverem o mundo Yanomami, um mundo que os brancos não conhecem, também são uma crítica a civilização dos brancos, o "povo da mercadoria" (KOPENAWA; ALBERT, 2016, p.410) que está empurrando planeta terra para uma catástrofe natural, o que a ciência ocidental vem entendendo como o Antropoceno (KELLY, 2017, p.1).

Existe mais um personagem (não-humano) importante do cosmos xamânico para entender os desdobramentos da cobiça dos brancos por minérios, a cobiça que faz os brancos cavarem cada vez mais fundo a terra em busca de minérios. Trata-se do espírito Xawari, que se refere aos "espíritos da epidemia" - os xawaripës (KOPENAWA; ALBERT, 2016, p.627). O espírito da epidemia é uma fumaça corrosiva liberada através das ações mineradoras dos brancos, "é um espírito maléfico que mata e come nossos filhos [...] é faminto de carne humana, não quer nem caça nem peixe, só gosta mesmo é da banha yanomami” (ALBERT, 2002, p.253). E, como não podia ser diferente, este espírito tem a aparência dos brancos (ALBERT, 2002, p.253).

\footnotetext{
${ }^{14} \mathrm{O}$ Antropoceno que foi proposto pelo biólogo Eugene F. e pelo químico Paul Crutzen, enquanto um novo período geológico que aponta para catástrofe ambiental. A antropóloga Anna Tsing escreve que um dos traços marcantes do Antropoceno é a dispersão descontrolada dos seres humanos, o que acaba por afetar negativamente as demais espécies (TSING, 2017, p.60).
} 
O ouro, enquanto mantido abaixo da terra, é algo que não causa problemas, mas quando exposto e retirado, gera a dispersão da fumaça, que através da alteração xamânica pode ser vista como espíritos que são perigosos para todos os seres da floresta, vista como espíritos devoradores de carne yanomami mais especificamente. De novo, a ação dos brancos como que desregula o sobrenatural, ou melhor, enfurece alguns espíritos que habitam o sobrenatural. Kopenawa diz que a fumaça vem se mostrando cada vez mais sem controle, e cada vez mais irada, “o vento leva-a até o céu. Quando chega lá, seu calor queima-o pouco a pouco e ele fura [...] como um saco de plástico derretendo no calor" (ALBERT, 2002, p.253).

Kopenawa, no capítulo "O céu e a floresta”, explica por qual motivo a floresta é "vasta e bela [...] impregnada de riqueza" (KOPENAWA; ALBERT, 2016, p.207), ou seja, o xamã explica por que a floresta amazônica é fértil e exuberante. No início, foi o primeiro xamã Omama o responsável por fazer uma distribuição das imagens que dão fertilidade à floresta por todos os seus cantos. Ne ropë (não-humano) é a imagem que dá fertilidade à floresta, "valor de" (ne), "rapidez" (rope), e que pode se relacionar com o xamã na forma de xapiri, então com o nome ne rope hi (KOPENAWA; ALBERT, 2016, p.631). Essa imagem é o agente que faz a floresta "acontecer", que faz as plantas crescerem, os frutos ficarem maduros. Essa imagem nunca está sozinha, pois a floresta é composta também pelas imagens das abelhas yamanama, das mulheres bananeiras aro kohi, dos gaviões witiwitima namo, e muitas outras mais (KOPENAWA; ALBERT, 2016, p.208), e são exatamente estes espíritos que a fumaça canibal tem afugentado, colocando em risco, assim, o frágil estado atual do cosmos. Ou seja, os espíritos (não-humanos) estão em uma guerra constante na floresta, e esta é uma guerra para a qual os brancos são cegos.

O gesto de Omama, que distribui os espíritos pela floresta na sua origem, ou o gesto xamânico, que vê espíritos por todos os lados das florestas, parecem redirecionar diretamente a questão "o que torna a floresta fértil?" para a questão “quem torna a floresta fértil?", ou seja, no xamanismo o que está em jogo é qual espírito torna a floresta viva, ou então quais espíritos mantêm a floresta encantada. Nada na floresta acontece, a não ser que uma conspiração de espíritos se associe para que aquilo exista. "Os brancos não conhecem a imagem do ser da chuva e seus filhos. Com certeza acham que a chuva cai do céu à toa! Eu, ao contrário, as contemplei muitas vezes em meus sonhos. As palavras da gente da floresta são outras" (KOPENAWA; ALBERT, 2016, p.198). Nada na floresta acontece por acaso, sem razão, pois isso seria algo como um "pensamento de ninguém" (KELLY, apud, VALENTIM, 2018, p.256), portanto, na floresta encantada tudo tem um ser animado em seu fundo, por trás de tudo está à ação de 
alguém, a ação de algo além dos humanos. Esta indicação é importante, pois se refere diretamente a uma ligação com o além dos humanos que os humanos brancos são incapazes de contemplar. A floresta xamânica pensa, ela é habitada por infinitos seres que pensam, e justamente por isso não pode ser tratada como um segundo plano, como um simples cenário para o pensamento, ela está muito mais próxima de ser outra sociedade, ou melhor, outras sociedades, tão importantes quanto as sociedades humanas. (DESCOLA, 2006, p.457). Neste cenário, é a pergunta; “Quem é a floresta?”, que se impõe.

Como Bensusan escreve, um dos axiomas das mônadas é que, tudo existe, ou deixa de existir, em função de agentes entendidos enquanto unidades básicas de ação (BENSUSAN, 2017, p.82). Sendo assim, é como se qualquer coisa que existe remetesse a uma razão, a um agente, ou então que qualquer coisa que exista só existe em função de múltiplos agentes, e então todas as questões acabam por chegar no "quem". Aproximando este axioma das monadologias, e o xamanismo, então, são os espíritos e não qualquer lei natural que faz as coisas acontecerem na floresta, e, logo, não existem princípios gerais que guiam a natureza, pois tudo/todos ali influenciam no caminho, na formação da floresta. Como resume o xamã de forma bruta: "na floresta, a ecologia somos nós" (KOPENAWA; ALBERT, 2016, p.480).

\section{Os diferentes Lévi-Strauss; entre o frio e o quente}

Lévi-Strauss explorou a relação entre a entropia e a antropologia. O binômio quente/frio foi construído pensando na entropia, pois são "modos de fazer" (SÁEZ, 2013, p.142) história que marcam uma diferença termodinâmica entre as diferentes sociedades. Com a diferença frio/quente, o antropólogo não quer se prender à distinção entre os antigos e os modernos e a como esta diferença é utilizada do modo clássico (como se existissem povos sem história e povos com história). O que se revela nas palavras do antropólogo são "modos de percepção diferentes de uma história que abrange a todos" (SÁEZ, 2013, p.140), então, de certo modo, pode-se dizer que todas sociedades estão $n a$ história (SZTUTMAN, 2005, p.89), mas de maneiras diferentes, com distintas posturas perante essa história. Mas o que seria esta história que, para o antropólogo, engloba todas as sociedades? A história é um processo de dissolução irreversível, é a entropia, é a defasagem, o antropólogo entende a história menos como construção do que como degradação (SÁEZ, 2013, p.144). As sociedades frias são as que lutam contra, as que resistem aos efeitos da degradação entrópica, enquanto as sociedades quentes aceleram os efeitos da degradação (SZTUTMAN, 2005, p.90). 
Assim, existem sociedades que retardam a entropia e outras que a aceleram, mas, como Sáez observa (SÁEZ, 2013, p.143), o antropólogo francês parece mais inclinado à degradação, ou seja, mesmo as sociedades frias não seriam fortes o bastante para segurar o processo entrópico que leva o universo a morte, é como se as sociedades frias ainda deixassem um mínimo de entropia acontecer, então, poderiam retardar a corrosão, mas não poderiam pará-la ${ }^{15}$. Como Renato Sztutman explica (2005, p.90), autores como Alfred Gell e Mauro Almeida também dizem que, de certa forma, todo o esforço contra a entropia não torna possível revertêla, ou seja, não é possível uma história perpétua, pois a passagem do tempo inevitavelmente corrói tudo o que existe pela frente. Logo, mesmo que a historicidade fria resista aos efeitos da entropia, ela não é forte o bastante a ponto de não ir pelo mesmo caminho do desgaste e da morte térmica.

O filósofo Valentim (2018, p.269), observa que existem dois Lévi-Strauss. Um primeiro que nos Tristes trópicos, levou até as últimas consequências a entropia para a antropologia, o que levou o antropólogo francês a até querer trocar o nome da disciplina para “entropologia" (LÉVI-STRAUSS, 1996, p.391). A antro(entro)pologia seria uma "disciplina dedicada a estudar em suas mais elevadas manifestações esse processo de desintegração" (LÉVI-STRAUSS, 1996, p.391). Nesta fase, é como se o antropólogo francês propusesse à humanidade como um todo, enquanto fortemente entrópica (VALENTIM, 2018, p.268), então nenhuma alteração antropológica (cultura-sociedade) seria capaz de conter a irreversibilidade que a entropia propõe, e resta ao homem enxugar o gelo, que um dia derreterá por inteiro. Mas Valentim faz ponderações importantes sobre um segundo Lévi-Strauss de $O$ pensamento selvagem, que então parece menos adepto do fatalismo entrópico, e que "apela à abertura a fontes exteriores, além da humanidade, como condição sine qua non para combater a entropia civilizatória" (VALENTIM, 2018, p.274), uma abertura da antropologia com efeitos sintrópicos fortes o bastante para competir com a entropia dos humanos, ou seja, um Lévi-Strauss adepto de uma antropologia enquanto possibilidade neguentrópica, uma antropologia contra a entropia. A antropologia, nesse sentido, é a possibilidade de, através de uma abertura ao exterior, seja para outros povos, mas, principalmente, para outras formas além dos humanos ${ }^{16}$, outras formas de vida, buscar uma reversão da flecha entrópica do tempo (VALENTIM, 2018, p.274).

\footnotetext{
${ }^{15}$ Esta indicação eu retirei da discussão que Sáez faz do binômio utilizado pelo antropólogo francês entre a máquina enquanto relógio ou enquanto uma máquina a vapor. (SÁEZ, 2013, p.143)

16 “Interromper seu labor de colmeia, captar a essência do que nossa espécie foi e continua a ser; na contemplação de um mineral mais bonito que todas as nossas obras, no perfume mais precioso do que nossos livros, aspirado na corola de um lírio, ou no piscar de olho cheio de paciência, de serenidade e de perdão
} 
A figura utilizada pelo filósofo brasileiro para explicar uma segunda fase do antropólogo francês, é a já clássica figura do "perpétuo desequilíbrio" (LÉVI-STRAUSS, 1993, p.215), a qual postula que nunca o sistema irá se estabilizar, então, as diferenças não são aplainadas, e nunca morrem entropicamente, pois é como se existisse uma flecha em direção à criação, e outra no sentido da destruição, sempre em desequilíbrio recíproco (VALENTIM, 2018, p.273).

A versão dos Tristes trópicos apresenta uma entropia ligada diretamente à antropia, como se o desenvolvimento da humanidade fosse necessariamente entrópico, uma espécie de Aentropia (VALENTIM, 2018, p.268), como escreve Valentim, na qual a antropia se mostra fortemente entrópica, e assim não resta espaço para um futuro que não tenda para a morte. Já em O pensamento selvagem, e nas articulações mais tardias do "perpétuo desequilíbrio" (LÉVISTRAUSS, 1993, p.215), está um Lévi-Strauss que pensa a possibilidade de uma força antientrópica, uma força em sentido contrário que nunca deixa o cosmos morrer, mantendo-o sempre em uma alternância de forças, onde as flechas contrárias sempre se mantêm assimétricas (VALENTIM, 2018, p.273). Como já visto através das palavras de Davi Kopenawa, é a atividade dos xamãs junto com vários outros espíritos que garantem o controle do alto teor destrutivo da civilização branca, então é como se a flecha do tempo trocasse de sentido de acordo com as variações dos mundos conflitantes (VALENTIM, 2018, p.286), o que, no caso, é o mundo dos espíritos contra o mundo dos brancos - xi wãri (sobrenatural), alteração radical, "vitalidade caósmica" (VALENTIM, 2018, p.286) contra xawara (sociedade branca), predação canibal, morte entrópica (VALENTIM, 2018, p.286). Para o xamã, a queda do céu não é um futuro necessário, ela pode acontecer, mas pode também não acontecer, e é importante frisar que o retorno ao caos não é uma morte termodinâmica, mas sim, uma espécie de vitalidade exponencial, uma positividade que cria uma nova atualização do cosmos, uma positividade que cria um novo cosmos. As indicações de Kopenawa, e do Lévi-Strauss tardio. parecem se alinhar, pois ambos apontam para uma saída da morte térmica do cosmos, e seja através do xamanismo, ou através da antropologia, em ambos os casos a saída está em uma abertura para os nãohumanos, uma abertura para além dos humanos.

Por fim, deve se atentar para as especificidades da catástrofe gerada pela queda do céu para Davi Kopenawa. Na suplantação do sistema através do caos, o que ocorre depois não é

recíproco, que um entendimento involuntário permite por vezes trocar com um gato" (LÉVI-STRAUSS, 1996, p.392). 
uma morte térmica do sistema, ou seja, não é que o caos por fim tira o movimento de tudo em uma morte entrópica clássica, pois o caos funciona como um reset no sistema, uma ação que reinicia o movimento, e que assim pode gerar um novo cosmos, com outros novos habitantes. E serão outros habitantes da floresta, e não outros brancos. O ser do caos e os brancos andam de mãos juntas, porém o xamã propõe que a queda do céu é apenas uma possibilidade, e não uma necessidade (VALENTIM, 2018, p.284). Este ponto é importante, pois marca uma diferença entre o sistema cósmico xamânico e os sistemas entrópicos ocidentais, que se encontram por todo o lado na modernidade, seja em parte da religião cristã, das ciências naturais, ou no materialismo histórico tardio.

Depois do desequilíbrio dos patamares celestes de hoje, outra ordem será estabelecida e será passível de controle pelos novos xamãs que surgirão. Depois do fim, outro fim, e depois, outro fim, e assim sucessivamente. O medo de Kopenawa não é o de uma estabilização térmica, mas sim de um desequilíbrio extremamente severo. E os espíritos, os não-humanos, todos aqueles que pensam para além dos humanos, são aqueles, que junto aos xamãs, impedem que a civilização dos brancos se torne mais pesada que o céu.

\section{Referências}

AGAMBEN, Giorgio. O aberto: o homem e o animal. Rio de janeiro: Civilização brasileira, 2011. $162 \mathrm{p}$.

ALBERT, Bruce. O ouro canibal e a queda do céu: uma crítica xamânica da economia política da natureza; In: ALBERT, Bruce; RAMOS, Alcida (Eds.). Pacificando o branco: cosmologias do contato no Norte-Amazônico. São Paulo: IMESP/IRD/Ed.UNESP, p. 239-274, 2002.

BENSUSAN, Hilan. Linhas de animismo futuro. Brasília: IEB Mil Folhas, 2017. 172 p.

BÍBlIA. Português. Bíblia sagrada. Trad. Padre Antônio Pereira de Figueiredo. São Paulo: Barsa. 1972. 2055 p.

CHAKRABARTY, Dipesh. O clima da história: quatro teses. São Paulo; Sopro, n. 91, p. 1-22, jul. 2013. Disponível em: http://culturaebarbarie.org/sopro/n91.html. Acesso em : 17 mar. 2019.

DANOWSKI, Déborah; VIVEIROS DE CASTRO, Eduardo. Há um mundo por vir? Ensaio sobre os medos e os fins. Florianópolis: Cultura e Barbárie, 2014. 159 p.

DESCOLA, Philippe. As lanças do crepúsculo: Relações Jivaro na Alta Amazônia. Trad. Dorothée de Bruchard. São Paulo: Cosac Naify, 2006. 520 p.

KELLY, José António. "A Queda do Céu”: O incomparável olhar Yanomami de Davi Kopenawa. [Entrevista concedida a] Ricardo Machado. IHU on-line - Instituto Humanitas Unisinos, p. 1-4. ago. 2017. Disponível em: http: / / www.ihu.unisinos.br/159- 
noticias/entrevistas/570809-o-incomparavel-olhar-yanomami-de-davi-kopenawa-entrevistaespecial-com-jose-antonio-kelly-luciani. Acesso em: 7 jul. 2019.

KOHN, Eduardo. How forests think: toward an Anthropology beyond the human. Los Angeles/London: University of California, 2013. 267 p.

KOPENAWA, Davi; ALBERT, Bruce. A queda do céu: palavras de um xamã yanomami. 1 reimpressão. São Paulo: Companhia das letras, 2016. 729 p.

KOPENAWA, Davi; GOMES, Ana Maria R. O cosmos segundo os Yanomami: Hutukara e Urihi. Belo Horizonte: Revista UFMG, v. 22, n. 1, p. 142-159, jan. 2015. Disponível em: https://www.ufmg.br/revistaufmg/downloads/22/11-Artigo-11-p142-159.pdf. Acesso em: 10 abril. 2019.

LEITE, Tainah Víctor. Pessoa e humanidade nas etnografias Yanomami. 2010. $184 \mathrm{f}$. Dissertação. (Mestrado em Antropologia Social) - Departamento de Ciências Sociais, Universidade Federal do Rio de Janeiro, Rio de Janeiro, 2010.

LÉVI-STRAUSS, Claude. O Pensamento Selvagem. Trad. Tânia Pellegrini. Campinas: Papirus, 1989. $100 \mathrm{p}$. 1993. $261 \mathrm{p}$.

História de Lince. Trad. Beatriz Perrone-Moisés. São Paulo: Companhia das Letras.

$\frac{}{456 \text { p. }}$. Tristes Trópicos, Trad. Rosa Freire d'Aguiar. São Paulo: Companhia das Letras. 1996.

. Antropologia estrutural dois. Trad. Beatriz Perrone-Moisés. São Paulo: Cosac Naify. 2013. $432 \mathrm{p}$.

LÖWY, Michael. Walter Benjamin: aviso de incêndio, uma leitura das teses "Sobre o conceito de historia”. São Paulo: Boitempo, 2005. 160 p.

ROMANDINI, Fabián Ludueña. A comunidade dos espectros: I. Antropotecnia. Florianópolis: Cultura e Barbárie, 2012a. 275 p.

Para além do princípio antrópico: por uma filosofia do Outside. Florianópolis: Cultura e Barbárie, 2012b. 64 p.

SÁEZ, Oscar. O nome e o tempo do Yaminawa: etnografia história dos Yaminawa do rio Acre. São Paulo: Editora UNESP, 2006. 480 p.

A história pictográfica. In; CAIXETA DE QUEIROZ, Ruben; NOBRE, R. F. (Orgs.). Lèvi-Strauss: leituras brasileiras. Belo Horizonte: Editora UFMG. 2013. p. 201-229.

STENGERS, Isabelle. No tempo das catástrofes. Trad. Eloisa Araújo Ribeiro. São Paulo: Cosac Naify, 2015. 160 p. 
SZTUTMAN, Renato. O profeta e o principal: A ação política ameríndia e seus personagens. 2005. 458 f. Tese. (Doutorado em Antropologia Social) - Departamento em Ciências Sociais, Universidade de São Paulo, São Paulo, 2005.

TSING, Anna. A threat to Holocene resurgence is a threat to livability. In: BRIGHTMAN, Marc; LEWIS, Jerome. (Orgs.). The Anthropology of sustainability: Beyond development and progress. London; Palgrave Macmillan. 2017. p. 51-66.

VALENTIM. Marco Antônio. Extramundanidade e sobrenatureza: ensaios de ontologia infundamental. Florianópolis: Cultura e Barbárie, 2018. 320 p. 